\title{
A New Integrated Fuzzy Multi-Criteria Decision Model for Performance Evaluation
}

\author{
Emel Kızılkaya Aydogan ${ }^{1}$, Ozgur Demirtas ${ }^{2}$, Metin Dagdeviren ${ }^{3}$ \\ ${ }^{1}$ Department of Industrial Engineering, Erciyes University, Kayseri, Turkey \\ ${ }^{2}$ Turkish Air Force, Kayseri, Turkey \\ ${ }^{3}$ Department of Industrial Engineering, Gazi University, Ankara, Turkey \\ Correspondence: Ozgur Demirtas (PhD), Turkish Air Force, Kayseri, Turkey
}

Received: January 20, 2015 Accepted: February 5, 2015 Online Published: February 28, 2015

doi:10.11114/bms.v1i1.704

URL: http://dx.doi.org/10.11114/bms.v1i1.704

\begin{abstract}
The perspective of competition in the high technology industry has changed impressively over the last two decades and the indicators which can be defined as the traditional indicators of business performance are insufficient today. So we have identified a new set of financial and non-financial performance indicators that can be used by firms and then, we developed a business performance measurement model. There may be relations and dependencies among the dimensions of performance. For this reason, performance evaluation should be conducted in a holistic manner. In this study, a hybrid method, Equated Priority Values (EPV), has been used to reflect the outcomes of the most commonly used approaches, including the modified Fuzzy Logarithmic Least Squares Method (modified fuzzy LLSM), Chang's Extent Analysis Method and Mikhailov's Fuzzy Prioritization Approach. A real world application is carried out to illustrate how the model can be utilized. The application could be interpreted as demonstrating the effectiveness and feasibility of the proposed model.
\end{abstract}

Keywords: performance evaluation, fuzzy analytic hierarchy process, multiple criteria decision making, aviation

\section{Introduction}

Because accurate and appropriate performance measurement is critical for judging the success or failure of a business, performance indicators must be carefully identified. Financial ratios (profitability, liquidity, solvency, etc.) of firms could be used to evaluate financial performance. In today's complex global competition environment, as Kao and Hung (2007) stated, the incorporation of non-financial performance indicators, such as the capability of manufacturing and human resource management, provides a clearer and more relevant picture of performance. Laitinen (2002) argued that evaluation of non-financial indicators (management style, leadership, work environment etc.) is essential for high technology firms to adapt to today's drastically competitive and global business environment, as well as to construct accurate and appropriate data on their business strategies.

We selected three aviation maintenance center firms which support logistics for Turkish Air Force and to evaluate their performance indicators and their weight in the total score, we interviewed the firms' and corporation's senior management cadre. Expectations from a performance measurement scale particularly involve high quality, flawless product, reliability, and on-time delivery. To develop our performance evaluation model, we first identified various dimensions of business performance and the corresponding indicators, both financial and non-financial, that are used to evaluate the firms according to the expectations in question. Thus, we identified five important dimensions of performance, which are Effectiveness, Efficiency, Quality, Profitability and Work Environment and each indicator has a set of performance sub-indicators.

In Section 2, we present a review of the previous studies on fuzzy AHP. Sections 2.1., 2.2. and 2.3. briefly explain the most commonly used approaches. Section 3 discusses the definitions and characteristics of performance measurement. Implementation of the developed integrated fuzzy multi-criteria decision model is presented in Section 4, in which performance indicators are defined corresponding to the requirements of aviation industry. In addition, a hybrid method is used to reflect the outcomes of all three approaches. Finally, Section 5 presents our suggestions. 


\section{A Review of the Previous Studies on Fuzzy AHP}

In this study, system performances of three aviation firms are compared by using FAHP. The vagueness of system performance evaluation according to the multi-criteria method creates a problem, which is solved by using the FAHP method. In the literature, fuzzy AHP has been widely used to solve many complicated decision-making problems. Van Laarhoven and Pedrycz (1983) developed an approach based on the fuzzy logarithmic least squares method (LLSM) to tackle with subjectivity in pair-wise comparison process. Later, Boender et al. (1989) modified Buckley's normalization method using a more robust approach. Xu (2000) proposed a fuzzy least-squares priority method where the fuzzy weights of indicators are obtained from the fuzzy judgment matrix. Mikhailov (2003) proposed a fuzzy preference programming method based on $\alpha$-cut approach to derive priorities from fuzzy pairwise comparisons. Chang (1992) propounded an extent analysis method, which has been widely used by researchers for its simplicity. Csutora and Buckley (2001) proposed a method to find fuzzy weights, which is a direct fuzzification of Saaty's $\lambda$ max method.

Lee et al. (2008) proposed a FAHP and balanced scorecard (BSC) approach to evaluate an information technology department using FAHP to obtain the relative importance of the four perspectives defined by BSC and the relative importance of the primary performance indicators from each perspective. Kong and Liu (2005) employed FAHP to develop an e-commerce website valuation method to evaluate the performance indicators of this website. Mikhailov and Tsvetinov (2004) developed a fuzzy prioritization method by using pair-wise comparison assessments rather than accurate numerical values of the comparisons for service evaluation. They argued that their method eliminates the need for additional collection and classifying procedures. Zhu et al. (1999) introduced a FAHP-related application to locate possible drilling sites for petroleum. Ayağ (2005) presented an AHP-based fuzzy simulation approach to evaluate a number of conceptual design alternatives for a new product development study. He used a FAHP method to reduce the conceptual design alternatives by eliminating the alternatives with scores lower than a predetermined constant value. The constant value was obtained by certain assumptions. In their research, Ertuğrul and Karakaşoğlu (2009) evaluated the financial performance of Turkish cement firms through FAHP and TOPSIS methods by using only financial ratios. Monitto et al. (2002) presented a FAHP method application to evaluate automated manufacturing systems for producing a mechanical part for automotive industry. Cheng (1996) evaluated naval tactical missile systems by fuzzy AHP based on the value of membership function. In this study, the scores were not directly assigned by the experts, and the grade values representing the performance scores were calculated by membership functions built on the data on missile performance.

Kahraman et al. (2004) used FAHP to compare catering service companies. They identified the most important criteria for customers by a questionnaire. Dağdeviren and Yüksel (2008) developed a FAHP model for behavior-based safety management. Güngör et al. (2008) proposed a personnel selection system based on FAHP. They also examined Yager's weighted method and compared the results with FAHP method. Kwong and Bai (2002) applied FAHP to determine the relative importance of customer requirements in quality function development. Bozbura et al. (2007) proposed a model based on FAHP for prioritizing human capital measurement indicators. To select a project among a number of possible alternatives, Enea and Piazza (2004) applied a constrained FAHP approach where only triangular fuzzy numbers with positive supports are taken into account. They argued that neglecting information derived from constraints yield results with greater uncertainty. Maier-Speredelozzi and $\mathrm{Hu}$ (2002) evaluated performances of manufacturing system alternatives using FAHP. Although there are numerous assumptions and the used data seems to be scanty in this research, it is found to be useful before making costly and irreversible decisions like building manufacturing systems. Huang et al. (2008) applied a FAHP model to select R\&D projects. They employed a simulation to understand the changes in judgments under different decision environments. Chan and Kumar (2007) developed a global supplier selection system based on fuzzy extended AHP. Their system solves the problem with a large number of criteria and attributes. Kuo et al. (2002) proposed a location selection system by integrating FAHP and artificial neural network.

\subsection{Modified Fuzzy LLSM Approach}

Wang et al. (2006) demonstrated the incorrectness of van Laarhoven and Predrycz's method and Bounder et al.'s approach to normalization of the local priorities. In their study, they compared their results with those of van Laarhoven and Predycz and Boender by re-examining the same numerical examples.

As revealed by a literature review on the fuzzy AHP approach, triangular fuzzy comparison matrix can be represented by 


$$
\tilde{A}=\left(\tilde{a}_{i j}\right)_{n x n}=\left[\begin{array}{lccc}
(1,1,1) & \left(l_{12}, m_{12}, u_{12}\right) & \ldots & \left(l_{1 n}, m_{1 n}, u_{1 n}\right) \\
\left(l_{21}, m_{21}, u_{21}\right) & (1,1,1) & \ldots & \left(l_{2 n}, m_{2 n}, u_{2 n}\right) \\
\cdot & \cdot & & \cdot \\
\cdot & \cdot & & \cdot \\
\cdot & \cdot & & \cdot \\
\left(l_{n 1}, m_{n 1}, u_{n 1}\right) & \left(l_{n 2}, m_{n 2}, u_{n 2}\right) & \ldots & (1,1,1)
\end{array}\right]
$$

where $\tilde{a}_{i j}=\left(l_{i j}, m_{i j}, u_{i j}\right)=\tilde{a}_{j i}^{-1}=\left(1 / u_{j i}, 1 / m_{j i}, 1 / l_{j i}\right)$ for $\mathrm{i}, \mathrm{j}=1, \ldots$ n and $\mathrm{i} \neq \mathrm{j}$.

At this point, the modified fuzzy LLSM is formulated as follows;

$$
\begin{aligned}
\operatorname{Min} J=\sum_{i=1}^{n} \sum_{j=1, j \neq i}^{n}\left(\left(\ln w_{i}^{L}-\ln w_{j}^{U}-\ln l_{i j}\right)^{2}+\right. & \left.\left(\ln w_{i}^{M}-\ln w_{j}^{M}-\ln m_{i j}\right)^{2}+\left(\ln w_{i}^{U}-\ln w_{j}{ }^{L}-\ln u_{i j}\right)^{2}\right) \quad \text { s.t. } \\
& w_{i}^{L}+\sum_{j=1, j \neq i}^{n} w_{j}^{U} \geq 1, \\
& w_{i}^{U}+\sum_{j=1, j \neq i}^{n} w_{j}^{L} \leq 1 \\
& \sum_{i=1}^{n} w_{i}^{M}=1 \\
& \sum_{i=1}^{n}\left(w_{i}^{L}+w_{i}^{U}\right)=2, \\
& w_{i}^{U} \geq w_{i}^{M} \geq w_{i}^{L}>0
\end{aligned}
$$

Which is a constrained nonlinear optimization model, which constraints are all linear? The optimum solution to the above model directly forms normalized fuzzy weights $\tilde{w}_{i}=\left(w_{i}{ }^{L}, w_{i}^{M}, w_{i}^{U}\right), \quad i=1, \ldots ., n$.

The global fuzzy weights can be obtained by solving the following two linear programming models and an equation for each alternative $\mathrm{A}_{\mathrm{i}}(\mathrm{i}=1, \ldots, \mathrm{n})$;

$$
\begin{gathered}
w_{A_{i}}^{L}=\underset{W \in \Omega_{w}}{\operatorname{Min}} \sum_{j=1}^{m} w_{i j}^{L} w_{j} i=1, \ldots ., n, \\
w_{A_{i}}^{U}=\underset{W \in \Omega_{w}}{\operatorname{Max}} \sum_{j=1}^{m} w_{i j}^{U} w_{j} i=1, \ldots ., n, \\
w_{A_{i}}^{M}=\sum_{j=1}^{m} w_{i j}^{M} w_{j}^{M} i=1, \ldots ., n,
\end{gathered}
$$

Where $\Omega_{w}=\left\{W=\left(w_{1}, \ldots, w_{m}\right)^{T} \mathrm{I} w_{j}^{L} \leq w_{j} \leq w_{j}^{U}, \sum_{j=1}^{m} w_{j}=1, j=1, \ldots, m\right\}$ is a set of weights. 


\subsection{Chang's Extent Analysis Method}

The steps of Chang's $(1992,1996)$ extent analysis approach are as follows: Let $X=\{x 1, x 2, \ldots, x n\}$ be an object set, and $\mathrm{U}=\{\mathrm{u} 1, \mathrm{u} 2, \ldots, \mathrm{um}\}$ be a goal set. According to the method in Chang's (1992) extent analysis, each object is taken and the extent analysis for each goal gi, is performed by order. Therefore, $\mathrm{m}$ extent analysis values for each object can be obtained with the following signs:

$$
M_{g i}^{1}, M_{g i}^{2}, \ldots, M_{g i}^{m}, \quad i=1,2, \ldots, n
$$

where all the $M_{g i}^{j}(j=1,2, \ldots, m)$ are TFNs.

The steps of Chang's extent analysis can be given as in the following:

Step 1: The value of fuzzy synthetic extent with respect to the $i$ th object is defined as

$$
S_{i}=\sum_{j=1}^{m} M_{g i}^{j} \otimes\left[\sum_{i=1}^{n} \sum_{j=1}^{m} M_{g_{i}}^{j}\right]^{-1}
$$

To obtain $\sum_{j=1}^{m} M_{g i}^{j}$, perform the fuzzy addition operation of m extent analysis values for a particular matrix such that

$$
\sum_{j=1}^{m} M_{g i}^{j}=\left(\sum_{j=1}^{m} l_{j}, \sum_{j=1}^{m} m_{j}, \sum_{j=1}^{m} u_{j}\right)
$$

And to obtain $\left[\sum_{i=1}^{n} \sum_{j=1}^{m} M_{g_{i}}^{j}\right]^{-1}$, perform the fuzzy addition operation of $M_{g i}^{j}(\mathrm{j}=1,2, \ldots, m)$ values such that

$$
\sum_{i=1}^{n} \sum_{j=1}^{m} M_{g_{i}}^{j}=\left(\sum_{i=1}^{n} l_{i}, \sum_{i=1}^{n} m_{i}, \sum_{i=1}^{n} u_{i}\right.
$$

and then compute the inverse of the vector in Eq. (8) as follows

$$
\left[\sum_{i=1}^{n} \sum_{j=1}^{m} M_{g_{i}}^{j}\right]^{-1}=\left(\frac{1}{\sum_{i=1}^{n} u_{i}}, \frac{1}{\sum_{i=1}^{n} m_{i}}, \frac{1}{\sum_{i=1}^{n} l_{i}}\right) .
$$

Step 2: The degree of possibility of $M_{2}=\left(l_{2}, m_{2}, u_{2}\right) \geq M_{1}=\left(l_{l}, m_{1}, u_{1}\right)$ is defined as

$$
\mathrm{V}\left(M_{2} \geq M_{1}\right)=\sup \left[\min \left(\mu_{M_{1}}(x), \mu_{M_{2}}(y)\right)\right.
$$

and can be equivalently expressed as follows:

$$
\mathrm{V}\left(M_{2} \geq M_{1}\right)=\operatorname{hgt}\left(M_{1} \cap M_{2}\right)=\mu_{M_{2}}(d)=\left\{\begin{array}{cc}
1, & \text { if } m_{2} \geq m_{1} \\
0, & \text { if } l_{1} \geq u_{2} \\
\frac{l_{1}-u_{2}}{\left(m_{2}-u_{2}\right)-\left(m_{1}-l_{1}\right)}, & \text { otherwise }
\end{array}\right.
$$

where $d$ is the ordinate of the highest intersection point $D$ between $\mu_{M_{1}}$ and $\mu_{M_{2}}$ (see Figure 1). 
To compare $M_{1}$ and $M_{2}$, we need both the values of $V\left(M_{1} \geq M_{2}\right)$ and $V\left(M_{2} \geq M_{1}\right)$.

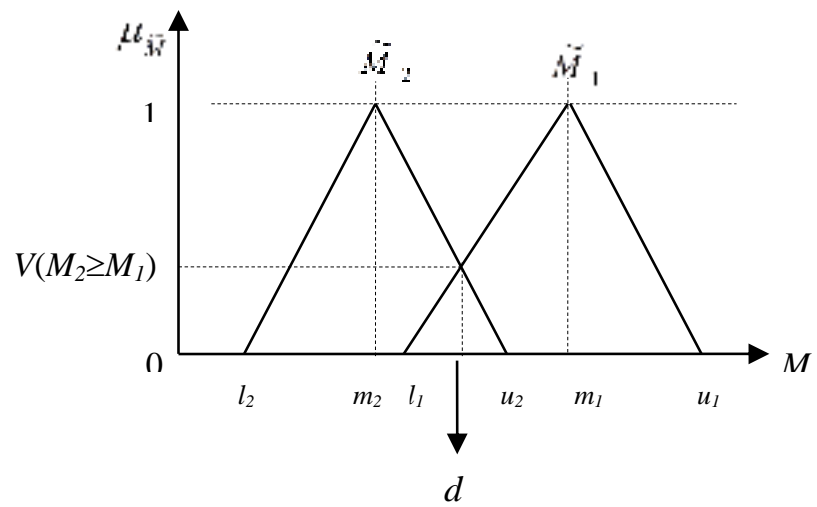

Figure 1. The intersection between $M_{1}$ and $M_{2}$

Step 3: The degree possibility for a convex fuzzy number to be greater than $k$ convex fuzzy numbers $M_{i}(i=1,2, \ldots, k)$ can be defined as

$$
V\left(M \geq M_{1}, M_{2}, \ldots, M_{k}\right)=V\left[\left(M \geq M_{l}\right) \text { and }\left(M \geq M_{2}\right) \text { and } \ldots \text { and }\left(M \geq M_{k}\right)\right]=\min V\left(M \geq M_{i}\right), \quad i=1,2, \ldots, \mathrm{k}
$$

Assume that

$$
d^{\prime}\left(A_{i}\right)=\min V\left(S_{i} \geq S_{k}\right.
$$

For $k=1,2, \ldots, n ; k \neq i$. Then the weight vector is given by

$$
W^{\prime}=\left(d^{\prime}\left(A_{1}\right), d^{\prime}\left(A_{2}\right), \ldots, d^{\prime}\left(A_{n}\right)\right)^{\mathrm{T}},
$$

where $A_{i}(i=1,2, \ldots, n)$ are $n$ elements.

Step 4: Via normalization, the normalized weight vectors are

$$
W^{\prime}=\left(d\left(A_{1}\right), d\left(A_{2}\right), \ldots, d\left(A_{n}\right)\right)^{\mathrm{T}}
$$

where $W$ is a nonfuzzy number.

\subsection{Mikhailov's Fuzzy Prioritization Approach}

The stages of Mikhailov's (2004) fuzzy prioritization approach are as follows:

Stage 1-Statement of the problem: Consider a prioritization problem with $n$ elements, where the pair-wise comparison judgments are represented by normal fuzzy sets or fuzzy numbers. Suppose that the decision-maker can provide a set $F=\left\{\tilde{a}_{i j}\right\}$ of $m \leq n(n-1) / 2$ fuzzy comparison judgments, $i=1,2, \ldots, n-1, \quad j=2,3, \ldots, n, j>i$, represented as triangular fuzzy numbers $\tilde{a}_{i j}=\left(l_{i j}, m_{i j}, u_{i j}\right)$.

The problem is to derive a crisp priority vector $w=\left(w_{1}, w_{2}, \ldots, w_{n}\right)^{\mathrm{T}}$, such that the priority ratios $w_{i} / w_{j}$ are approximately within the scopes of the initial fuzzy judgments, or

$$
l_{i j} \widetilde{\leq} \frac{w_{i}}{w_{j}} \widetilde{\leq} u_{i j}
$$

where the symbol $\tilde{\leq}$ denotes the statement 'fuzzy less or equal to'.

Stage 2- Assumptions of the fuzzy prioritization method: Membership functions that represent the decision maker's satisfaction with different crisp solution ratios $w_{i} / w_{j}$ could be introduced. Each crisp priority vector $w$ satisfies the double-side inequality (16) with some degree, which can be measured by a membership function, linear with respect to 
the unknown ratio $w_{i} / w_{j}$

$$
\mu_{i j}\left(\frac{w_{i}}{w_{j}}\right)= \begin{cases}\frac{\left(w_{i} / w_{j}\right)-l_{i j}}{m_{i j}-l_{i j}}, & \frac{w_{i}}{w_{j}} \leq m_{i j} \\ \frac{u_{i j}-\left(w_{i} / w_{j}\right)}{u_{i j}-m_{i j}}, & \frac{w_{i}}{w_{j}} \geq m_{i j}\end{cases}
$$

In order to avoid dividing by zero, it is assumed that $u_{i j} \geq m_{i j} \geq l_{i j}$. Actually, this is not a binding assumption, since certain judgments can be represented as triangular fuzzy numbers with very small scope $\delta_{i j}=\left(u_{i j}\right.$, $\left.l_{i j}\right)$. Obviously, the scopes of the fuzzy judgments correspond to the degree of uncertainty of the decision-maker with respect to comparison ratios.

The membership function (17) is linearly increasing over the interval $\left(-\infty, m_{i j}\right)$ and linearly decreasing over the interval $\left(m_{i j}, \infty\right)$. Contrary to the triangular fuzzy number's membership function, the above function takes negative values when $w_{i} / w_{j}<l_{i j}$ or $w_{i} / w_{j}>u_{i j}$ and has a maximum value $\mu_{i j}=1$ at $w_{i} / w_{j}=m_{i j}$. Over the range $\left(l_{i j}, u_{i j}\right)$, the membership function (17) coincides with the fuzzy triangular judgment $\tilde{a}_{i j}=\left(l_{i j}, m_{i j}, u_{i j}\right)$.

The solution to the prioritization problem by the FPP method is based on two main assumptions. The first one requires the existence of nonempty fuzzy feasible area $P$ on the $(n-1)$-dimensional simplex $Q^{n-1}$

$$
Q^{n-1}=\left\{\left(w_{1}, w_{2}, \ldots, w_{n}\right) \mid w_{i}>0, \sum_{i=1}^{n} w_{i}=1\right\},
$$

defined as an intersection of the membership functions, similar to (17) and the simplex hyperplane (18). The membership function of the fuzzy feasible area is given by

$$
\mu_{P}(w)=\min _{i j}\left\{\mu_{i j}(w) / i=1,2, \ldots, n-1 ; j=2, \ldots, n ; j>i\right\}
$$

By defining the membership functions (17) as $L$-fuzzy sets $\{\mathrm{L}=[-\infty, 1]\}$, the assumption of non-emptiness of $P$ on the simplex could be relaxed. If the fuzzy judgments are very inconsistent, then $\mu_{P}(w)$ could take negative values for all normalized priority vectors $w \in Q^{n-1}$.

The second assumption of the FPP method specifies a selection rule, which determines a priority vector with the highest degree of membership in the aggregated membership function (19). It can easily be proved that $\mu_{P}(w)$ is a convex set, so there is always a priority vector $w^{*} \in Q^{n-1}$ with a maximum degree of membership

$$
\lambda^{*}=\mu_{p}\left(w^{*}\right)=\max _{w \in Q^{n-1}} \min _{i j}\left\{\mu_{i j}(w)\right\} .
$$

Stage 3- Solving the fuzzy prioritization problem: The solution procedure of the proposed method is based on the maximum decision rule, known from the game theory. The maximum rule has also been applied by Bellman and Zadeh (1970) for solving decision-making problems in uncertain environments. Zimmermann (1990) used the same decision rule for fuzzy linear problems with soft constraints and shows that if the membership functions representing the soft constraints are linear, the maximum problem can be transformed into a linear programming problem. Similar linear formulations of the prioritization problem are given in Mikhailov (2000, 2003).

The maximum prioritization problem (20) can be represented in the following way;

maximize $\lambda$

subject to

$$
\begin{gathered}
\lambda \leq \mu_{i j}(w), \\
i=1,2, \ldots, n-1, \quad j=2,3, \ldots, n, \quad j>i,
\end{gathered}
$$




$$
\sum_{l=1}^{n} w_{l}=1, \quad w_{l}>0, l=1,2, \ldots, n
$$

(21)

Taking into consideration the specific form of the membership functions (17), the problem (21) can be further transformed into a bilinear program of the type;

maximize $\lambda$

subject to

$$
\begin{gathered}
\left(m_{i j}-l_{i j}\right) \lambda w_{j}-w_{i}+l_{i j} w_{j} \leq 0, \\
\left(u_{i j}-m_{i j}\right) \lambda w_{j}+w_{i}-u_{i j} w_{j} \leq 0, \\
\sum_{k=1}^{n} w_{k}=1, \quad w_{k}>0, k=1,2, \ldots, n . \\
i=1,2, \ldots, n-1, \quad j=2,3, \ldots, n, \quad j>i .
\end{gathered}
$$

The optimal solution to the above non-linear problem $\left(\lambda^{*}, w^{*}\right)$ might be obtained by employing some appropriate numerical method for non-linear optimization.

The optimal value $\lambda^{*}$, if it is positive, indicates that all solution ratios completely satisfy the fuzzy judgment, i.e. $l_{i j} \leq$

$\left(w_{i}^{*} / w_{j}^{*}\right) \leq u_{i j}$, which means that the initial set of fuzzy judgments is rather consistent. A negative value of $\lambda^{*}$ shows

that the solution ratios approximately satisfy all double-side inequalities (16), i.e. the fuzzy judgments are strongly inconsistent. Therefore, the optimal value $\lambda^{*}$ can be used for measuring the consistency of the initial set of fuzzy judgments.

\section{Performance Measurement and Characteristics of Good Performance Measures}

There are several definitions of performance measurement. The changes in the definitions particularly result from complexities of globalized world conditions. In a simple environment, performance measurement is not hard to perform successfully. However, at present, where there are many factors and unexpected changes take place incessantly, it is very hard to perform.

Bourne et al (2003) described performance measurement as the process of assessing progress toward achieving predetermined goals. It is typically conducted by program or agency management. In US Government Accountability Office Glossary (2005) performance measurement and evaluation are comprehensively explained. It is stated that performance measures may address the type or level of activities conducted, the direct products and services delivered by a program, or the results of those products and services. The definition is considered to properly explain its attributes. Performance measurement focuses on the program's achievement to satisfy the predetermined objectives. Performance evaluations may investigate the factors in the program that may contribute to its achievement and also illustrate the relations between all important events like inputs, outputs, value-added and non-value-added activities.

There are many types of measurement tools to determine how well a program performs. Gamble et al. (2007) developed a comprehensive method for measuring the performance of organizations. They argued that a company's performance depends on its strategic plan. Some measurements involve basic financial ratios such as profitability ratios, growth ratios and financial leverage ratios etc. Since qualitative factors such as human resource management, customer satisfaction and innovativeness are hard to measure and their weights are very important in today's business environment, these factors must be taken into consideration in the model. The traditional performance measurement system in the business environment is losing its power in today's fast changing environment. Organizations are attempting to get re-shaped into more flat hierarchies. As a result, performance measurement will be more difficult with an organizational hierarchy with multi-functional attributes which are increasing in complexity.

Development of performance measures can be complex. Useful, workable measures must balance a variety of characteristics which are difficult to achieve simultaneously. Geerken (2008) cited the following among important characteristics of good performance measures: Goal-focused; the measure must be an indicator of the achievement of an organization goal. The goal should be accepted as important by citizens and public officials outside your organization. 
Feasible; the measure must be possible to implement. The organization must have the subject matter expertise, time, personnel, technical capability, and access to the information necessary to implement the measure. Inexpensive, implementation of the measure must be relatively inexpensive, or it will compete for resources needed to accomplish your organization's goals. Understandable; the measure must be clear and simple enough to be successfully communicated to, and understood by non-experts. Accurate; the measure must accurately capture the events or condition it is supposed to be an indicator of. Valid; the measure must be designed to minimize bias, error, and distortion. Project Linked; causal links must be established between the project and the measures of organizational goal achievement.

\section{Developing Integrated Fuzzy Multi-Criteria Decision Model}

There are a number of firms that satisfy the requirements of Turkish Aviation Industry. These requirements also serve firms in different sectors. We selected three aviation maintenance center firms which support logistics for Turkish Air Force to evaluate their performance indicators and their weights in the total score. For this purpose, we interviewed the senior management cadre of the firms and the corporation. Expectations from a performance measurement scale particularly involve high quality, flawless product, reliability and delivery on time. To develop our performance evaluation model, we first identified various dimensions of business performance and the corresponding indicators, both financial and non-financial, that are used to evaluate these firms according to the expectations in question. Thus, we identified five important dimensions of performance, which are Effectiveness, Efficiency, Quality, Profitability and Work Environment. Each main indicator has a set of sub-indicators. Below are the definitions of these main and sub-indicators;

Effectiveness (EFV) is an indicator of whether the objectives are determined and the work performed comply with documentations and programs and whether such work is executed with desired quality, on time and with intended quantity. Simply, it is the relation between the intended and realized outcome. Three sub-indicators of the main indicator Effectiveness are Production Rate (PR) (number of manufactured parts), Retardation Rate (RR) (delay time for a needed part) and Unplanned Production Rate (UPR) (the rate of the parts produced unplanned).

Efficiency (EFF) is an indicator of how well a firm handles production resources such as human, material, machine and capital in the production process or service production process. Three sub-indicators of the main indicator Efficiency are Manpower Capacity (MC) (available manpower capacity), Spare Part Supply Rate (SPS) (the rate of spare parts provided) and Workbench Usage Rate (WU) (available workbench time).

Quality $(\mathrm{Q})$ is the congruity between performed actions and determined standards of objectives. It can be briefly defined as the degree of meeting the quality expectations. Four sub-indicators of the main indicator Quality are Defective Product Rate (DP) (the rate of defective finished parts), Production Defect Rate (PD) (the defect rate of products in the production line), Personnel Certification (PC) (the rate of certified personnel) and Quality Cost (QC) (the cost of providing quality).

Profitability (P) generally refers to earning money from the activities for the benefit of the business. From this perspective, profitability is an indicator of a firm's ability to earn profits. Three sub-indicators of the main indicator Profitability are Value-Added per Person (PV) (average value of an employee's direct contribution to obtain the finished product), Stable Estate Profit (EP) (profit from stable estate) and Labor Profit Rate (LP) (rate of an employee's contribution to total added value).

Work Environment (WE) is an indicator of employees' behaviors and opinions concerning different system factors such as physical working conditions, leadership, collaborative work conditions, communication etc. Three sub-indicators of the main indicator Work Environment are Work Accident (WA) (work accident quantity), Manpower Cycle Rate (MC) (the rate of leaving personnel) and Environment Sensitiveness (ES) (firms' adherence to environmental regulations).

We arranged a hierarchical structure for the performance indicators with the senior management cadre of the firms and the corporation, which is presented in Figure 2. 


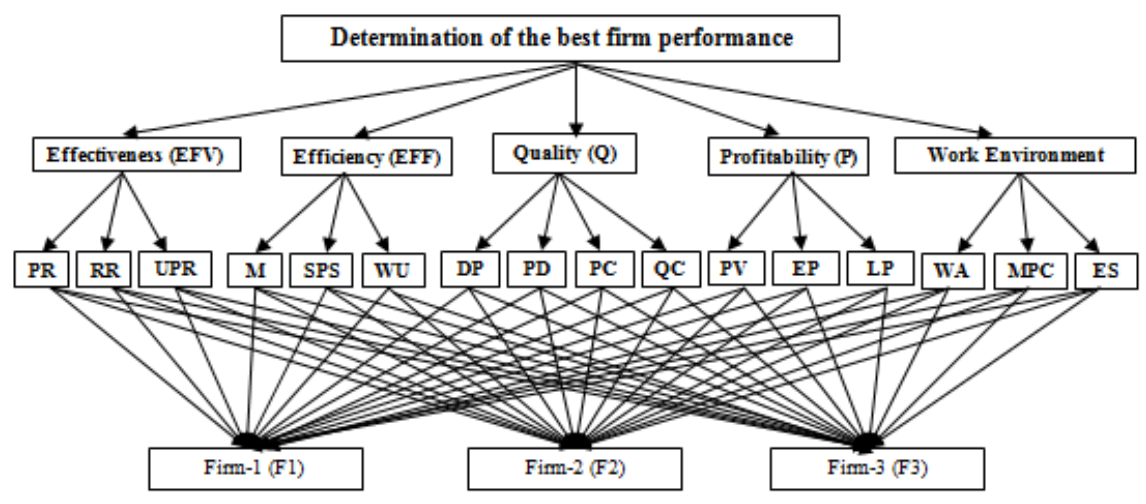

Figure 2. The hierarchical structure for the performance indicators

Following the hierarchical structure, we prepared a questionnaire and conducted surveys based on face-to-face interviews with 13 managers. Appendix A provides some examples of the completed questionnaires. The managers made pair-wise comparisons by answering the questions in the questionnaire. We used the results of the survey to generate fuzzy comparison matrices. Fuzzy comparison tables are presented in Appendix B using these data. The local weights for the five main indicators and global weights of the three aviation firms with respect to the objective for modified Fuzzy LLSM, Chang's Extent Analysis and Mikhailov's Prioritization Approach are given in Tables 1, 2 and 3, respectively.

Table 1. Synthesis of local weights by the modified fuzzy LLSM

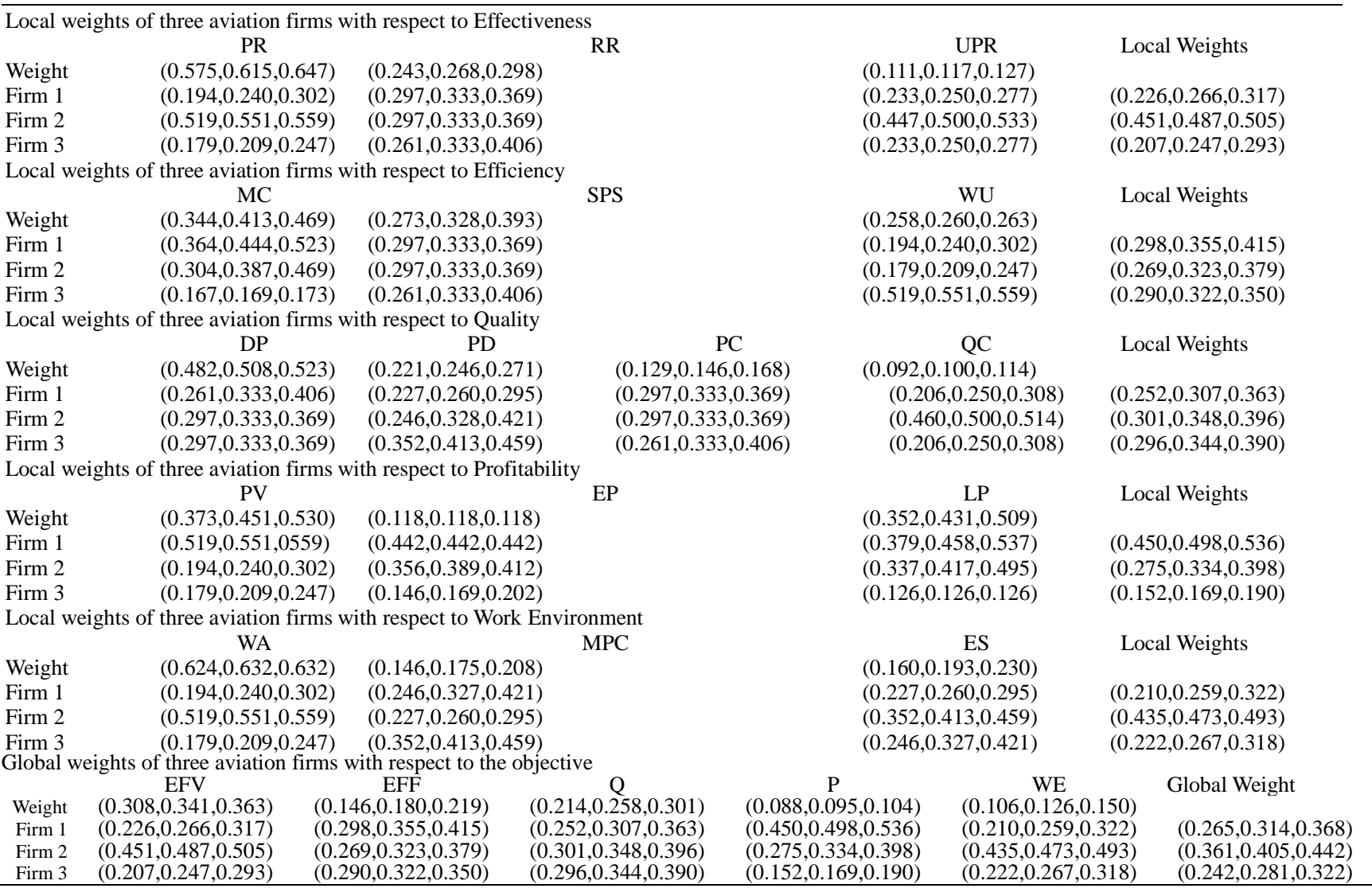


Table 2. Synthesis of local weights by the extent analysis method.

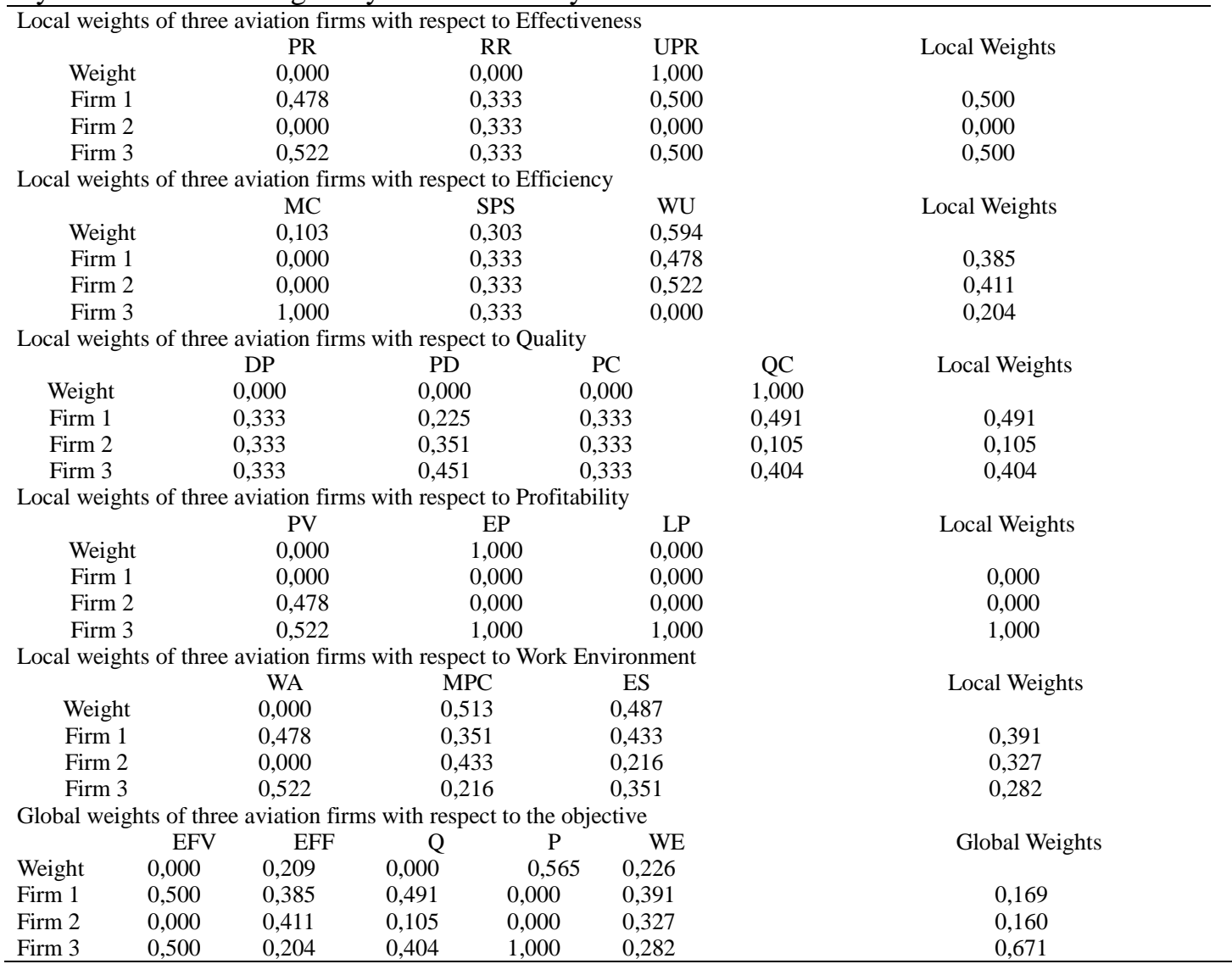

Table 3. Synthesis of local weights by Mikhailov's method

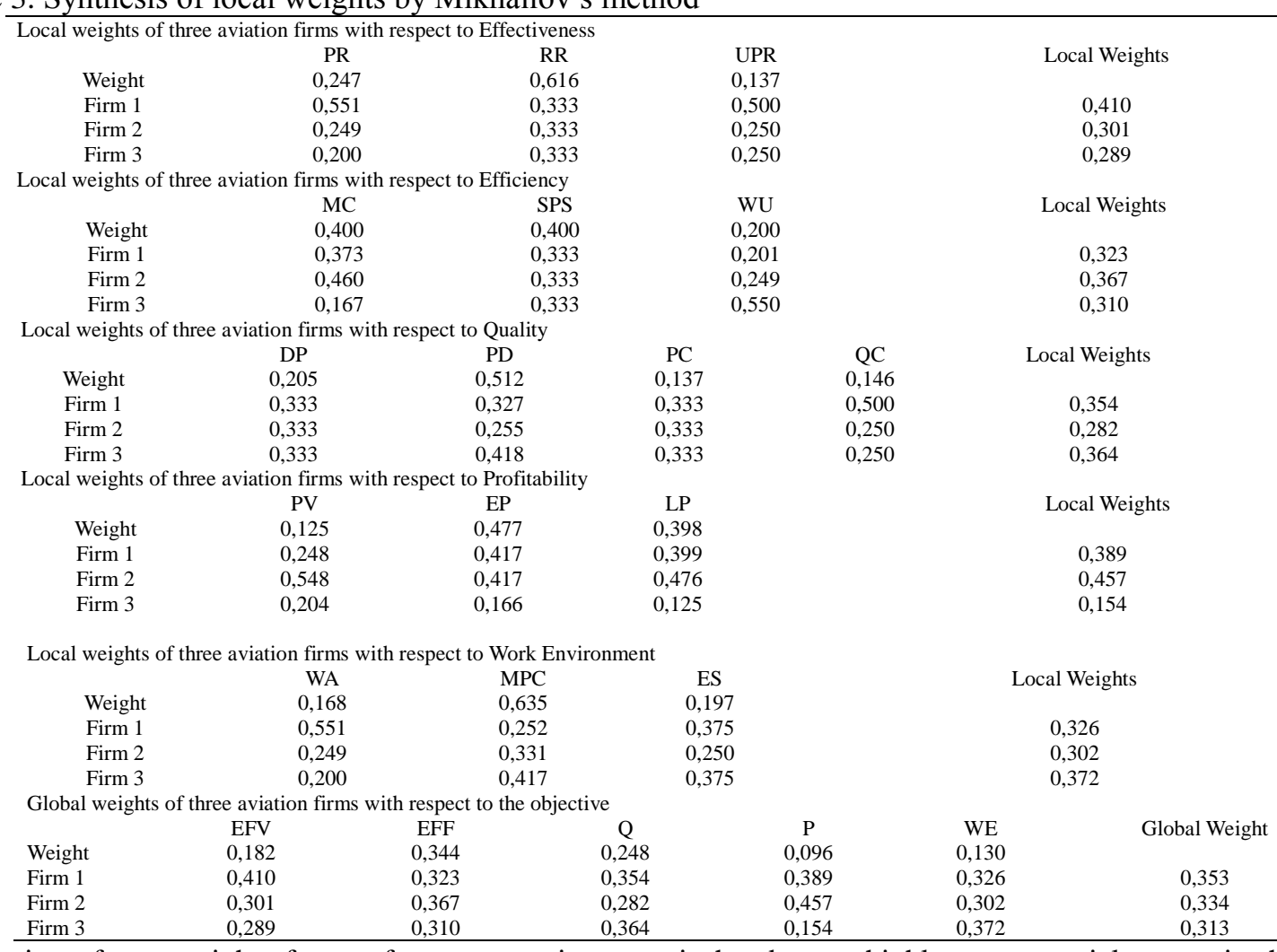

Estimation of true weights from a fuzzy comparison matrix has been a highly controversial matter in the literature. Wang et al.(2006) demonstrated that Chang's extent analysis method cannot estimate the true weights from a fuzzy 
comparison matrix and has led to several misapplications in the literature. However, Chang's extent analysis method is still being implemented successfully in the literature. Mikhailov's fuzzy prioritization approach is another method widely used in the literature. So deciding which fuzzy decision method will be used for performance evaluation is quite difficult.

In this study, we used a hybrid method that equally involves the outcomes of the three methods. The proposed EPV method offers a compromise solution that takes into account both the advantages and disadvantages of these methods most commonly used in the literature.

The EPV method is an average of the global weights of these three methods. The values are given in Table 4. Table 4. Global Weights and EPVM's of the Three Aviation Firms

\begin{tabular}{lcccc}
\hline & $\begin{array}{c}\text { Modified fuzzy } \\
\text { LLSM }\end{array}$ & Extent Analysis & Mikhailov's Method & $\begin{array}{c}\text { Equated Priority } \\
\text { Value Method } \\
\text { (EPV) }\end{array}$ \\
\hline Firm 1 & 0,315 & 0,169 & 0,353 & 0,279 \\
Firm 2 & 0,404 & 0,160 & 0,334 & 0,299 \\
Firm 3 & 0,281 & 0,671 & 0,313 & 0,422 \\
\hline
\end{tabular}

As can seen in Table 4, Modified fuzzy LLSM chose Firm 2; Extent Analysis Method chose Firm 3; Mikhailov's Method chose Firm 1 and the hybrid method chose Firm 3. This new method gives top priority to Firm 3 and the least priority to Firm1.

\section{Conclusion}

As we show in our model, the environment of the aviation industry is too complex to evaluate sufficiently, and is considerably different from other business environments. For example, profitability has the least importance among the main indicators. Effectiveness and quality are the most important attributes, respectively. Such discrepancies result from the specific business environment of defense industries.

Our model can successfully evaluate firm performances because EPV is calculated by getting an average of the global weights of the three methods, which is more unbiased to make accurate comparisons. The change in the best alternative when EPV is taken into account has shown that EPV consistently constitutes an important phase in decision-making process.

We hope that our findings will be convenient for decision makers in tangible and intangible multi-criteria circumstances and help high technology manufacturers and service executives in determining their companies' strengths and weaknesses so that they can deploy firm strategies leading to further improvements in their business operations.

\section{References}

Ayağ, Z. (2005). A fuzzy AHP-based simulation approach to concept evaluation in a NPD environment. IIE Transactions, 37, 827-842. http://dx.doi.org/10.1080/07408170590969852

Bellman R. E., \& Zadeh, L. A. (1970). Decision-making in a fuzzy environment. Management Science, 17, $141-164$. http://dx.doi.org/10.1287/mnsc.17.4.B141

Boender, C. G. E., De Graan, J. G., \& Lootsma, F. A. (1989). Multi-criteria decision analysis with fuzzy pairwise comparisons. Fuzzy Sets and Systems, 29, 133-143. http://dx.doi.org/10.1016/0165-0114(89)90187-5

Bourne, M., Franco, M., \& Wilkes, J. (2003). Corporate performance management. Measuring Business Excellence, 7, 3-15. http://dx.doi.org/10.1108/13683040310496462

Bozbura, F. T., Beskese, A., \& Kahraman, C. (2007). Prioritization of human capital measurement indicators using fuzzy AHP. Expert Systems with Applications, 32, 1100-1112. http://dx.doi.org/10.1016/j.eswa.2006.02.006

Chan, F. T. S., \& Kumar, N. (2007). Global supplier development considering risk factors using fuzzy extended AHP-based approach. Omega, 35, 417-431. http://dx.doi.org/10.1016/j.omega.2005.08.004

Chang, D. Y. (1992). Extent analysis and synthetic decision. Optimization techniques and applications. Singapore: World Scientific.

Chang, D. Y., (1996). Applications of the extent analysis method on fuzzy AHP. European Journal of Operational Research, 95, 649-655. http://dx.doi.org/10.1016/0377-2217(95)00300-2 
Cheng, C. H. (1996). Evaluating naval tactical missile systems by fuzzy AHP based on the grade value of membership function. European Journal of Operational Research, 96, 343-350. http://dx.doi.org/10.1016/S0377-2217(96)00026-4

Csutora, R., \& Buckley, J. J. (2001). Fuzzy hierarchical analysis: The Lamda-Max method. Fuzzy Sets and Systems, 120, 181-195. http://dx.doi.org/10.1016/S0165-0114(99)00155-4

Dagdeviren, M., \& Yüksel, I. (2008). Developing a fuzzy analytic hierarchy process (AHP) model for behavior-based safety management. Information Science, 178, 1717-1733. http://dx.doi.org/10.1016/j.ins.2007.10.016

Enea, M., \& Piazza, T. (2004). Project selection by constrained fuzzy AHP. Fuzzy Optimization and Decision Making, 3, 39-62. http://dx.doi.org/10.1023/B:FODM.0000013071.63614.3d

Ertuğrul, İ., \& Karakaşoğlu, N. (2009). Performance evaluation of Turkish cement firms with fuzzy analytic hierarchy process and TOPSIS methods. Expert Systems with Applications, 36, 702-715. http://dx.doi.org/10.1016/j.eswa.2007.10.014

Gamble, J., Strickland, A., \& Thompson, A. (2007). Crafting \& Executing Strategy. New York: McGraw-Hill.

Geerken, M. (2008). Performance measurement for justice information system projects. Bureau of Justice Assistance. Texas: Texas State University.

Güngör, Z., Serhadlıoğlu, G., \& Kesen, S. H. (2008). A fuzzy AHP approach to personnel selection problem. Applied Soft Computing Journal. http://dx.doi.org/10.1016/j.asoc.2008.09.003

Huang, C. C., Chu, P. Y., \& Chiang, Y. H. (2008). A fuzzy AHP application in government-sponsored R \& Dproject selection. Omega, 36, 1038-1052. http://dx.doi.org/10.1016/j.omega.2006.05.003

Kahraman, C., Cebeci, U., \& Ruan, D. (2004). Multi-attribute comparison of catering service companies using fuzzy AHP: The case of Turkey. Int. J. Production Economics, 87, 171-184. http://dx.doi.org/10.1016/S0925-5273(03)00099-9

Kao, C., \& Hung, H. T. (2007). Management performance: an empirical study of the manufacturing companies in Taiwan, Omega. International Journal of Management Science, 35 (2), 152-160.

Kingsbury, N., R. (2005). Performance measurement and evaluation. US Government Accountability Office Glossary.

Kong, F., \& Liu, H. (2005). Applying fuzzy analytic hierarchy process to evaluate success factors of e-commerce. International Journal of Information and Systems Sciences, 1(3-4), 406-412.

Kuo, R. J., Chi, S. C., \& Kao, S. S. (2002). A decision support system for selecting convenience store location through integration of fuzzy AHP and artificial neural network. Computers in Industry, 47, 199-214. http://dx.doi.org/10.1016/S0166-3615(01)00147-6

Kwong, C. K., \& Bai, H. A. (2002). fuzzy AHP approach to the determination of importance weights of customer requirements in quality function deployment. Journal of Intelligent Manufacturing, 13, 367-377. http://dx.doi.org/10.1023/A:1019984626631

Laitinen, E. A. (2002). Dynamic performance measurement system: evidence from small Finnish technology companies. Scandinavian Journal of Management, $18 \quad$ (1), $\quad$ 65-99. http://dx.doi.org/10.1016/S0956-5221(00)00021-X

Lee, A. H. I., Chen, W. C., \& Chang, C. J. (2008). A fuzzy AHP and BSC approach for evaluating performance of IT department in the manufacturing industry in Taiwan. Expert Systems with Applications, 34, 96-107. http://dx.doi.org/10.1016/j.eswa.2006.08.022

Maier-Speredelozzi, V., \& Hu, S. J. (2002). Selecting manufacturing system configurations based on performance using AHP. Society of Manufacturing Engineers, 179, 1-8.

Mikhailov, L. (2000). A fuzzy programming method for deriving priorities in the analytic hierarchy process. Journal of Operational Research Society, 51, 341-349. http://dx.doi.org/10.1057/palgrave.jors.2600899 
Mikhailov, L. (2003). Deriving priorities from fuzzy pairwise comparison judgments. Fuzzy Sets and Systems, 134, 365-385. http://dx.doi.org/10.1016/S0165-0114(02)00383-4

Mikhailov, L., \& Tsvetinov, P. (2004). Evaluation of services using a fuzzy analytic hierarchy process. Applied Soft Computing, 5, 23-33. http://dx.doi.org/10.1016/j.asoc.2004.04.001

Monitto, M., Pappalardo, P., \& Tolio T. (2002). A new Fuzzy AHP method for the evaluation of automated manufacturing systems. Annals of the CIRP 2002, $51 \quad$ (1), 395-398. http://dx.doi.org/10.1016/S0007-8506(07)61545-5

Van Laarhoven, P. J. M., \& Pedrycz, W. A. (1983). Fuzzy extension of Saaty's priority theory. Fuzzy Sets and Systems, 11, 229-241. http://dx.doi.org/10.1016/S0165-0114(83)80082-7

Wang, Y. M., Elhag, T. M. S., \& Hua, Z. S. (2006). A modified fuzzy logarithmic least squares method for fuzzy analytic hierarchy proces. Fuzzy Sets and Systems, 157, 3055-3071. http://dx.doi.org/10.1016/j.fss.2006.08.010

Wang, Y. M., Luo, Y., \& Hua, Z. S. (2008). On the extent analysis method for fuzzy AHP and its applications. European Journal of Operational Research, 186, 735-747. http://dx.doi.org/10.1016/j.ejor.2007.01.050

$\mathrm{Xu}$, R. (2000). Fuzzy least-squares priority method in the analytic hierarchy process. Fuzzy Sets and Systems, 112, 359-404. http://dx.doi.org/10.1016/S0165-0114(97)00376-X

Zimmermann, H. J. (1990). Fuzzy Set Theory and its Application. Kluwer Academic Publishers, 35-85.

Zhu, K. J., Jing, Y., \& Chang, D. Y. (1999). A discussion on extent analysis method and applications of fuzzy AHP. European Journal of Operational Research, 116, 450-456. http://dx.doi.org/10.1016/S0377-2217(98)00331-2 
Appendix A. Examples from completed questionnaires

With respect to the overall objective "Determination of the best firm performance"

Q1 How important is effectiveness (EFV) when it is compared to Efficiency (EFF)?

Q2 How important is effectiveness (EFV) when it is compared to Quality $(\mathrm{Q})$ ?

Q3 How important is effectiveness (EFV) when it is compared to Profitability (P)?

Q4 How important is effectiveness (EFV) when it is compared to Work Environment (WE)?

Q5 How important is efficiency (EFF) when it is compared to Quality (Q)?

Q6 How important is efficiency (EFF) when it is compared to Profitability $(\mathrm{P})$ ?

Q7 How important is efficiency (EFF) when it is compared to Work Environment (WE)?

Q8 How important is Quality (Q) when it is compared to Profitability (P)?

Q9 How important is Quality (Q) when it is compared to Work Environment (WE)?

Q10 How important is Profitability (P) when it is compared to Work Environment (WE)?

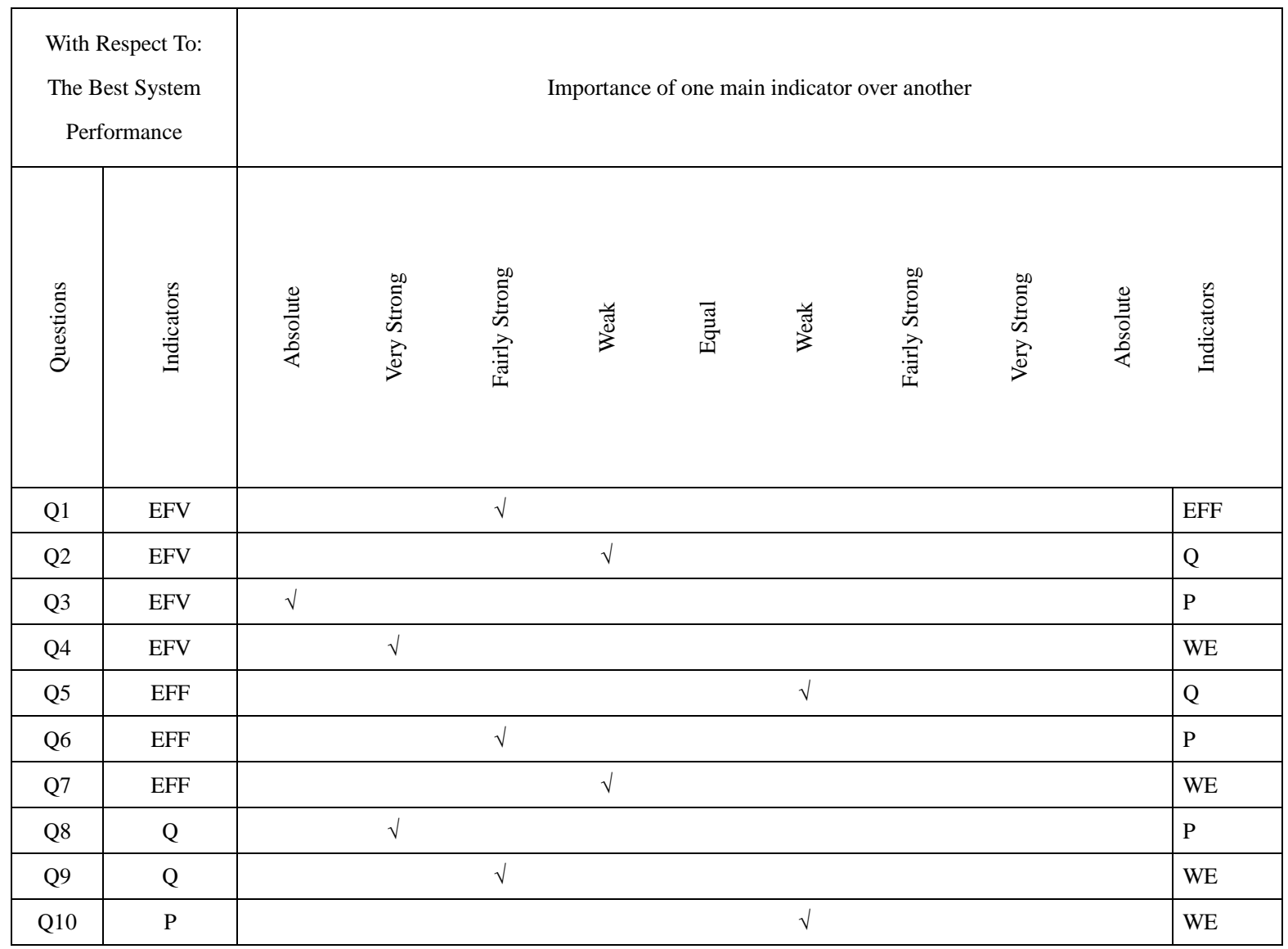


With respect to the main attribute "Effectiveness (EFV)"

Q11 How important is production rate (PR) when it is compared to retardation rate (RR)?

Q12 How important is production rate (PR) when it is compared to unplanned production rate (UPR)?

Q13 How important is retardation rate (RR) when it is compared to unplanned production rate (UPR)?

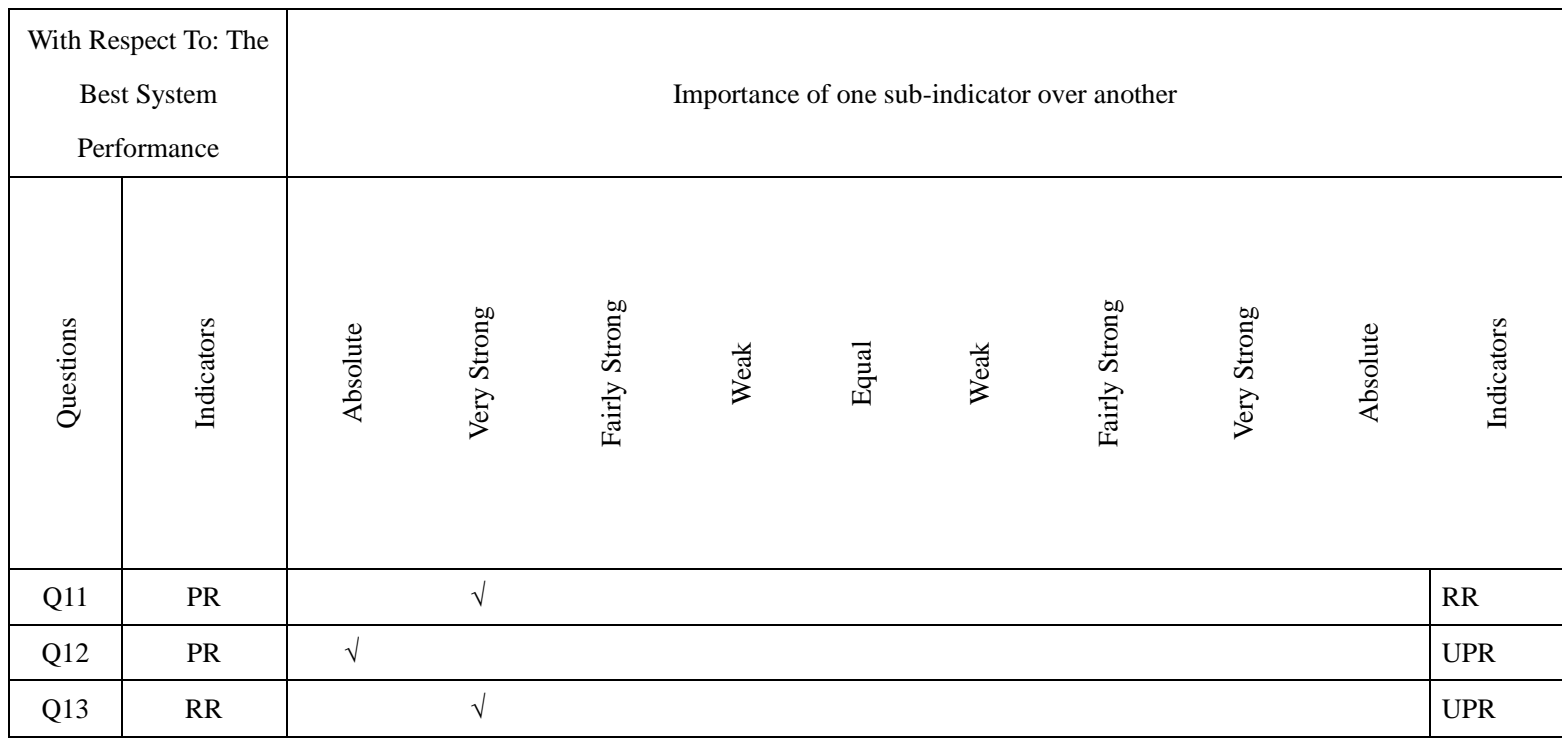

With respect to the sub-attribute "Production Rate (PR)"

Q29 How important is Firm-1 (F1) when it is compared to Firm-2 (F2)?

Q30 How important is Firm-1 (F1) when it is compared to Firm-3 (F3)?

Q31 How important is Firm-2 (F2) when it is compared to Firm-3 (F3)?

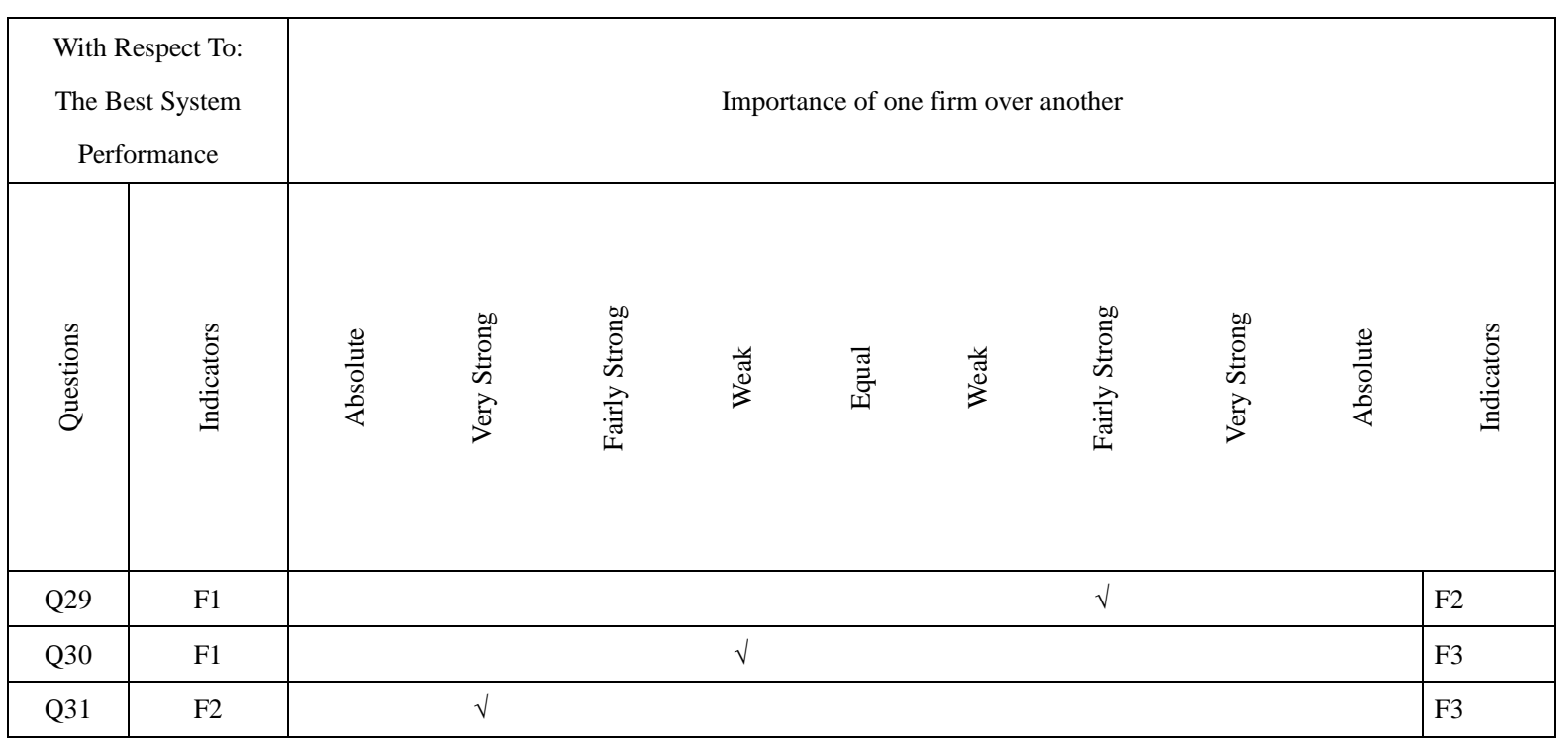


Appendix B: Fuzzy comparison tables

Table 1. Fuzzy comparison matrix of five decision indicator with respect to objective and its modified fuzzy LLSM

\begin{tabular}{lccccccccc}
\hline Criteria & EFV & EFF & Q & P & WE & Modified fuzzy LLSM & $\begin{array}{l}\text { Extent } \\
\text { Analysis }\end{array}$ & Mikhailov \\
& & & & & & & & \\
\hline EFV & $(1,1,1)$ & $(3 / 2,2,5 / 2)$ & $(2 / 3,1,3 / 2)$ & $(7 / 2,4,9 / 2)$ & $(5 / 2,3,7 / 2)$ & $(0.308,0.341,0.363)$ & 0,000 & 0,182 \\
EFF & $(2 / 5,1 / 2,2 / 3)$ & $(1,1,1)$ & $(2 / 3,1,3 / 2)$ & $(3 / 2,2,5 / 2)$ & $(2 / 3,1,3 / 2)$ & $(0.146,0.180,0.219)$ & 0,209 & 0,344 \\
Q & $(2 / 3,1,3 / 2)$ & $(2 / 3,1,3 / 2)$ & $(1,1,1)$ & $(5 / 2,3,7 / 2)$ & $(3 / 2,2,5 / 2)$ & $(0.214,0.258,0.301)$ & 0,000 & 0,248 \\
P & $(2 / 9,1 / 4,2 / 7)$ & $(2 / 5,1 / 2,2 / 3)$ & $(2 / 7,1 / 3,2 / 5)$ & $(1,1,1)$ & $(2 / 3,1,3 / 2)$ & $(0.088,0.098,0.104)$ & 0,565 & 0,096 \\
WE & $(2 / 7,1 / 3,2 / 5)$ & $(2 / 3,1,3 / 2)$ & $(2 / 5,1 / 2,2 / 3)$ & $(2 / 3,1,3 / 2)$ & $(1,1,1)$ & $(0.106,0.126,0.150)$ & 0,226 & 0,130 \\
\hline
\end{tabular}

Table 2. Fuzzy comparison matrix of three sub-indicators with respect to Effectiveness and its modified fuzzy LLSM

\begin{tabular}{llllllll}
\hline Criteria & \multicolumn{1}{c}{ PR } & \multicolumn{1}{c}{ RR } & \multicolumn{1}{c}{ UPR } & Modified fuzzy LLSM & Extent Analysis & \multicolumn{2}{c}{ Mikhailov } \\
\hline PR & $(1,1,1)$ & $(5 / 2,3,7 / 2)$ & $(7 / 2,4,9 / 2)$ & $(0.575,0.615,0.647)$ & 0,000 & 0,247 \\
RR & $(2 / 7,1 / 3,2 / 5)$ & $(1,1,1)$ & $(5 / 2,3,7 / 2)$ & $(0.243,0.268,0.298)$ & 0,000 & 0,616 \\
UPR & $(2 / 9,1 / 4,2 / 7)$ & $(2 / 7,1 / 3,2 / 5)$ & $(1,1,1)$ & $(0.111,0.117,0.127)$ & 1,000 & 0,137 \\
\hline
\end{tabular}

Table 3. Fuzzy comparison matrix of three sub-indicators with respect to Efficiency and its modified fuzzy LLSM

\begin{tabular}{lccccccc}
\hline Criteria & MC & SPS & WU & Modified fuzzy LLSM & Extent Analysis & Mikhailov \\
\hline MC & $(1,1,1)$ & $(2 / 3,1,3 / 2)$ & $(3 / 2,2,5 / 2)$ & $(0.344,0.413,0.469)$ & 0,103 & 0,400 \\
SPS & $(2 / 3,1,3 / 2)$ & $(1,1,1)$ & $(1,1,1)$ & $(0.273,0.328,0.393)$ & 0,303 & 0,400 \\
WU & $(2 / 5,1 / 2,2 / 3)$ & $(1,1,1)$ & $(1,1,1)$ & $(0.258,0.260,0.263)$ & 0,594 & 0,200 \\
\hline
\end{tabular}

Table 4. Fuzzy comparison matrix of three sub-indicators with respect to Quality and its modified fuzzy LLSM

\begin{tabular}{llllllll}
\hline Criteria & \multicolumn{1}{c}{ DP } & \multicolumn{1}{c}{ PD } & \multicolumn{1}{c}{ PC } & QC & Modified fuzzy LLSM & Extent Analys & Mikhailor \\
\hline DP & $(1,1,1)$ & $(5 / 2,3,7 / 2)$ & $(7 / 2,4,9 / 2)$ & $(5 / 2,3,7 / 2)$ & $(0.482,0.508,0.523)$ & 0,000 & 0,205 \\
PD & $(2 / 7,1 / 3,2 / 5)$ & $(1,1,1)$ & $(3 / 2,2,5 / 2)$ & $(5 / 2,3,7 / 2)$ & $(0.221,0.246,0.271)$ & 0,000 & 0,512 \\
PC & $(2 / 9,1 / 4,2 / 7)$ & $(2 / 5,1 / 2,2 / 3)$ & $(1,1,1)$ & $(3 / 2,2,5 / 2)$ & $(0.129,0.146,0.168)$ & 0,000 & 0,137 \\
QC & $(2 / 7,1 / 3,2 / 5)$ & $(2 / 7,1 / 3,2 / 5)$ & $(2 / 5,1 / 2,2 / 3)$ & $(1,1,1)$ & $(0.092,0.100,0.114)$ & 1,000 & 0,146 \\
\hline
\end{tabular}

Table 5. Fuzzy comparison matrix of three sub-indicators with respect to Profitability and its modified fuzzy LLSM

\begin{tabular}{lcccccc}
\hline Criteria & PV & EP & LP & Modified fuzzy LLSM & Extent Analysis & Mikhailo \\
\hline PV & $(1,1,1)$ & $(7 / 2,4,9 / 2)$ & $(2 / 3,1,3 / 2)$ & $(0.373,0.451,0.530)$ & 0,000 & 0,125 \\
EP & $(2 / 9,1 / 4,2 / 7)$ & $(1,1,1)$ & $(2 / 7,1 / 3,2 / 5)$ & $(0.118,0.118,0.118)$ & 1,000 & 0,477 \\
LP & $(2 / 3,1,3 / 2)$ & $(7 / 2,4,9 / 2)$ & $(1,1,1)$ & $(0.352,0.431,0.509)$ & 0,000 & 0,398
\end{tabular}

Table 6. Fuzzy comparison matrix of three sub-indicators with respect to Work Environment and its modified fuzzy LLSI

\begin{tabular}{lcccccc}
\hline Criteria & WA & MPC & ES & Modified fuzzy LLSM & Extent Analysis & Mikhailov \\
WA & $(1,1,1)$ & $(7 / 2,4,9 / 2)$ & $(5 / 2,3,7 / 2)$ & $(0.624,0.632,0.632)$ & 0,000 & 0,168 \\
MPC & $(2 / 9,1 / 4,2 / 7)$ & $(1,1,1)$ & $(2 / 3,1,3 / 2)$ & $(0.146,0.175,0.208)$ & 0,513 & 0,635 \\
ES & $(2 / 7,1 / 3,2 / 5)$ & $(2 / 3,1,3 / 2)$ & $(1,1,1)$ & $(0.160,0.193,0.230)$ & 0,487 & 0,197
\end{tabular}

Table 7. Fuzzy comparison matrix of three sub-indicators with respect to Production Rate and its modified fuzzy LLSM

\begin{tabular}{lcccccc}
\hline Criteria & Firm 1 & Firm 2 & Firm 3 & Modified fuzzy LLSM & Extent Analysis & Mikhailov \\
\hline Firm 1 & $(1,1,1)$ & $(2 / 5,1 / 2,2 / 3)$ & $(2 / 3,1,3 / 2)$ & $(0.194,0.240,0.302)$ & 0,478 & 0,551 \\
Firm 2 & $(3 / 2,2,5 / 2)$ & $(1,1,1)$ & $(5 / 2,3,7 / 2)$ & $(0.519,0.551,0.559)$ & 0,000 & 0,249 \\
Firm 3 & $(2 / 3,1,3 / 2)$ & $(2 / 7,1 / 3,2 / 5)$ & $(1,1,1)$ & $(0.179,0.209,0.247)$ & 0,522 & 0,200 \\
\hline
\end{tabular}

Table 8. Fuzzy comparison matrix of three sub-indicators with respect to Retardation Rate and its modified fuzzy LLSM

\begin{tabular}{lcccccc}
\hline Criteria & Firm 1 & Firm 2 & Firm 3 & Modified fuzzy LLSM & Extent Analysis & Mikhailov \\
\hline Firm 1 & $(1,1,1)$ & $(1,1,1)$ & $(2 / 3,1,3 / 2)$ & $(0.297,0.333,0.369)$ & 0,333 & 0,333 \\
Firm 2 & $(1,1,1)$ & $(1,1,1)$ & $(2 / 3,1,3 / 2)$ & $(0.297,0.333,0.369)$ & 0,333 & 0,333 \\
Firm 3 & $(2 / 3,1,3 / 2)$ & $(2 / 3,1,3 / 2)$ & $(1,1,1)$ & $(0.261,0.333,0.406)$ & 0,333 & 0,333 \\
\hline
\end{tabular}


Table 9. Fuzzy comparison matrix of three sub-indicators with respect to Unplanned Production Rate and its modified fuzzy LLSM

\begin{tabular}{lcccccc}
\hline Criteria & Firm 1 & Firm 2 & Firm 3 & Modified fuzzy LLSM & Extent Analysis & Mikhailov \\
\hline Firm 1 & $(1,1,1)$ & $(2 / 5,1 / 2,2 / 3)$ & $(1,1,1)$ & $(0.233,0.250,0.277)$ & 0,500 & 0,500 \\
Firm 2 & $(3 / 2,2,5 / 2)$ & $(1,1,1)$ & $(3 / 2,2,5 / 2)$ & $(0.447,0.500,0.533)$ & 0,000 & 0,250 \\
Firm 3 & $(1,1,1)$ & $(2 / 5,1 / 2,2 / 3)$ & $(1,1,1)$ & $(0.233,0.250,0.277)$ & 0,500 & 0,250 \\
\hline
\end{tabular}

Table 10. Fuzzy comparison matrix of three sub-indicators with respect to Manpower Capacity and its modified fuzzy LLSM

\begin{tabular}{lcccccc}
\hline Criteria & Firm 1 & Firm 2 & Firm 3 & Modified fuzzy LLSM & Extent Analysis & Mikhailov \\
\hline Firm 1 & $(1,1,1)$ & $(2 / 3,1,3 / 2)$ & $(5 / 2,3,7 / 2)$ & $(0.364,0.444,0.523)$ & 0,000 & 0,373 \\
Firm 2 & $(2 / 3,1,3 / 2)$ & $(1,1,1)$ & $(3 / 2,2,5 / 2)$ & $(0.304,0.387,0.469)$ & 0,000 & 0,460 \\
Firm 3 & $(2 / 7,1 / 3,2 / 5)$ & $(2 / 5,1 / 2,2 / 3)$ & $(1,1,1)$ & $(0.167,0.169,0.173)$ & 1,000 & 0,167 \\
\hline
\end{tabular}

Table 11. Fuzzy comparison matrix of three sub-indicators with respect to Spare Part Supply Rate and its modified fuzzy LLSM

\begin{tabular}{lcccccc}
\hline Criteria & Firm 1 & Firm 2 & Firm 3 & Modified fuzzy LLSM & Extent Analysis & Mikhailov \\
\hline Firm 1 & $(1,1,1)$ & $(1,1,1)$ & $(2 / 3,1,3 / 2)$ & $(0.297,0.333,0.369)$ & 0,333 & 0,333 \\
Firm 2 & $(1,1,1)$ & $(1,1,1)$ & $(2 / 3,1,3 / 2)$ & $(0.297,0.333,0.369)$ & 0,333 & 0,333 \\
Firm 3 & $(2 / 3,1,3 / 2)$ & $(2 / 3,1,3 / 2)$ & $(1,1,1)$ & $(0.261,0.333,0.406)$ & 0,333 & 0,333 \\
\hline
\end{tabular}

Table 12. Fuzzy comparison matrix of three sub-indicators with respect to Workbench Usage and its modified fuzzy LLSM

\begin{tabular}{lcccccc}
\hline Criteria & Firm 1 & Firm 2 & Firm 3 & Modified fuzzy LLSM & Extent Analysis & Mikhailov \\
\hline Firm 1 & $(1,1,1)$ & $(2 / 3,1,3 / 2)$ & $(2 / 5,1 / 2,2 / 3)$ & $(0.194,0.240,0.302)$ & 0,478 & 0,201 \\
Firm 2 & $(2 / 3,1,3 / 2)$ & $(1,1,1)$ & $(2 / 7,1 / 3,2 / 5)$ & $(0.179,0.209,0.247)$ & 0,522 & 0,249 \\
Firm 3 & $(3 / 2,2,5 / 2)$ & $(5 / 2,3,7 / 2)$ & $(1,1,1)$ & $(0.519,0.551,0.559)$ & 0,000 & 0,550 \\
\hline
\end{tabular}

Table 13. Fuzzy comparison matrix of three sub-indicators with respect to Defective Product Rate and its modified fuzzy LLSM

\begin{tabular}{lcccccc}
\hline Criteria & Firm 1 & Firm 2 & Firm 3 & Modified fuzzy LLSM & Extent Analysis & Mikhailov \\
\hline Firm 1 & $(1,1,1)$ & $(2 / 3,1,3 / 2)$ & $(2 / 3,1,3 / 2)$ & $(0.261,0.333,0.406)$ & 0,333 & 0,333 \\
Firm 2 & $(2 / 3,1,3 / 2)$ & $(1,1,1)$ & $(1,1,1)$ & $(0.297,0.333,0.369)$ & 0,333 & 0,333 \\
Firm 3 & $(2 / 3,1,3 / 2)$ & $(1,1,1)$ & $(1,1,1)$ & $(0.297,0.333,0.369)$ & 0,333 & 0,333 \\
\hline
\end{tabular}

Table 14. Fuzzy comparison matrix of three sub-indicators with respect to Production Defect Rate and its modified fuzzy LLSM

\begin{tabular}{lcccccc}
\hline Criteria & Firm 1 & Firm 2 & Firm 3 & Modified fuzzy LLSM & Extent Analysis & Mikhailov \\
\hline Firm 1 & $(1,1,1)$ & $(2 / 3,1,3 / 2)$ & $(2 / 5,1 / 2,2 / 3)$ & $(0.227,0.260,0.295)$ & 0,225 & 0,327 \\
Firm 2 & $(2 / 3,1,3 / 2)$ & $(1,1,1)$ & $(2 / 3,1,3 / 2)$ & $(0.246,0.328,0.421)$ & 0,324 & 0,255 \\
Firm 3 & $(3 / 2,2,5 / 2)$ & $(2 / 3,1,3 / 2)$ & $(1,1,1)$ & $(0.352,0.413,0.459)$ & 0,451 & 0,418 \\
\hline
\end{tabular}

Table 15. Fuzzy comparison matrix of three sub-indicators with respect to Personnel Certification Rate and its modified fuzzy LLSM

\begin{tabular}{lcccccc}
\hline Criteria & Firm 1 & Firm 2 & Firm 3 & Modified fuzzy LLSM & Extent Analysis & Mikhailov \\
\hline Firm 1 & $(1,1,1)$ & $(1,1,1)$ & $(2 / 3,1,3 / 2)$ & $(0.297,0.333,0.369)$ & 0,333 & 0,333 \\
Firm 2 & $(1,1,1)$ & $(1,1,1)$ & $(2 / 3,1,3 / 2)$ & $(0.297,0.333,0.369)$ & 0,333 & 0,333 \\
Firm 3 & $(2 / 3,1,3 / 2)$ & $(2 / 3,1,3 / 2)$ & $(1,1,1)$ & $(0.261,0.333,0.406)$ & 0,333 & 0,333 \\
\hline
\end{tabular}

Table 16. Fuzzy comparison matrix of three sub-indicators with respect to Quality Cost and its modified fuzzy LLSM

\begin{tabular}{lcccccc}
\hline Criteria & Firm 1 & Firm 2 & Firm 3 & Modified fuzzy LLSM & Extent Analysis & Mikhailov \\
\hline Firm 1 & $(1,1,1)$ & $(2 / 5,1 / 2,2 / 3)$ & $(2 / 3,1,3 / 2)$ & $(0.206,0.250,0.308)$ & 0,491 & 0,500 \\
Firm 2 & $(3 / 2,2,5 / 2)$ & $(1,1,1)$ & $(3 / 2,2,5 / 2)$ & $(0.460,0.500,0.514)$ & 0,105 & 0,250 \\
Firm 3 & $(2 / 3,1,3 / 2)$ & $(2 / 5,1 / 2,2 / 3)$ & $(1,1,1)$ & $(0.206,0.250,0.308)$ & 0,404 & 0,250 \\
\hline
\end{tabular}


Table 17. Fuzzy comparison matrix of three sub-indicators with respect to Value-added Per Person and its modified fuzzy LLSM

\begin{tabular}{lcccccc}
\hline Criteria & Firm 1 & Firm 2 & Firm 3 & Modified fuzzy LLSM & Extent Analysis & Mikhailov \\
\hline Firm 1 & $(1,1,1)$ & $(3 / 2,2,5 / 2)$ & $(5 / 2,3,7 / 2)$ & $(0.519,0.551,0559)$ & 0,000 & 0,248 \\
Firm 2 & $(2 / 5,1 / 2,2 / 3)$ & $(1,1,1)$ & $(2 / 3,1,3 / 2)$ & $(0.194,0.240,0.302)$ & 0,478 & 0,548 \\
Firm 3 & $(2 / 7,1 / 3,2 / 5)$ & $(2 / 3,1,3 / 2)$ & $(1,1,1)$ & $(0.179,0.209,0.247)$ & 0,522 & 0,204 \\
\hline
\end{tabular}

Table 18. Fuzzy comparison matrix of three sub-indicators with respect to Stable Estate Profit and its modified fuzzy LLSM

\begin{tabular}{lcccccc}
\hline Criteria & Firm 1 & Firm 2 & Firm 3 & Modified fuzzy LLSM & Extent Analysis & Mikhailov \\
\hline Firm 1 & $(1,1,1)$ & $(1,1,1)$ & $(5 / 2,3,7 / 2)$ & $(0.442,0.442,0.442)$ & 0,000 & 0,417 \\
Firm 2 & $(1,1,1)$ & $(1,1,1)$ & $(3 / 2,2,5 / 2)$ & $(0.356,0.389,0.412)$ & 0,000 & 0,417 \\
Firm 3 & $(2 / 7,1 / 3,2 / 5)$ & $(2 / 5,1 / 2,2 / 3)$ & $(1,1,1)$ & $(0.146,0.169,0.202)$ & 1,000 & 0,166 \\
\hline
\end{tabular}

Table 19. Fuzzy comparison matrix of three sub-indicators with respect to Labor Profit and its modified fuzzy LLSM

\begin{tabular}{lcccccc}
\hline Criteria & Firm 1 & Firm 2 & Firm 3 & Modified fuzzy LLSM & Extent Analysis & Mikhailov \\
\hline Firm 1 & $(1,1,1)$ & $(2 / 3,1,3 / 2)$ & $(7 / 2,4,9 / 2)$ & $(0.379,0.458,0.537)$ & 0,000 & 0,399 \\
Firm 2 & $(2 / 3,1,3 / 2)$ & $(1,1,1)$ & $(5 / 2,3,7 / 2)$ & $(0.337,0.417,0.495)$ & 0,000 & 0,476 \\
Firm 3 & $(2 / 9,1 / 4,2 / 7)$ & $(2 / 7,1 / 3,2 / 5)$ & $(1,1,1)$ & $(0.126,0.126,0.126)$ & 1,000 & 0,125 \\
\hline
\end{tabular}

Table 20. Fuzzy comparison matrix of three sub-indicators with respect to Work Accident and its modified fuzzy LLSM

\begin{tabular}{lcccccc}
\hline Criteria & Firm 1 & Firm 2 & Firm 3 & Modified fuzzy LLSM & Extent Analysis & Mikhailov \\
\hline Firm 1 & $(1,1,1)$ & $(2 / 5,1 / 2,2 / 3)$ & $(2 / 3,1,3 / 2)$ & $(0.194,0.240,0.302)$ & 0,478 & 0,551 \\
Firm 2 & $(3 / 2,2,5 / 2)$ & $(1,1,1)$ & $(5 / 2,3,7 / 2)$ & $(0.519,0.551,0.559)$ & 0,000 & 0,249 \\
Firm 3 & $(2 / 3,1,3 / 2)$ & $(2 / 7,1 / 3,2 / 5)$ & $(1,1,1)$ & $(0.179,0.209,0.247)$ & 0,522 & 0,200 \\
\hline
\end{tabular}

Table 21. Fuzzy comparison matrix of three sub-indicators with respect to Manpower Cycle and its modified fuzzy LLSM

\begin{tabular}{lcccccc}
\hline Criteria & Firm 1 & Firm 2 & Firm 3 & Modified fuzzy LLSM & Extent Analysis & Mikhailov \\
\hline Firm 1 & $(1,1,1)$ & $(2 / 3,1,3 / 2)$ & $(2 / 3,1,3 / 2)$ & $(0.246,0.327,0.421)$ & 0,351 & 0,252 \\
Firm 2 & $(2 / 3,1,3 / 2)$ & $(1,1,1)$ & $(2 / 5,1 / 2,2 / 3)$ & $(0.227,0.260,0.295)$ & 0,433 & 0,331 \\
Firm 3 & $(2 / 3,1,3 / 2)$ & $(3 / 2,2,5 / 2)$ & $(1,1,1)$ & $(0.352,0.413,0.459)$ & 0,216 & 0,417 \\
\hline
\end{tabular}

Table 22. Fuzzy comparison matrix of three sub-indicators with respect to Environment Sensitiveness and its modified fuzzy LLSM

\begin{tabular}{lcccccc}
\hline Criteria & Firm 1 & Firm 2 & Firm 3 & Modified fuzzy LLSM & Extent Analysis & Mikhailov \\
\hline Firm 1 & $(1,1,1)$ & $(2 / 5,1 / 2,2 / 3)$ & $(2 / 3,1,3 / 2)$ & $(0.227,0.260,0.295)$ & 0,433 & 0,375 \\
Firm 2 & $(3 / 2,2,5 / 2)$ & $(1,1,1)$ & $(2 / 3,1,3 / 2)$ & $(0.352,0.413,0.459)$ & 0,216 & 0,250 \\
Firm 3 & $(2 / 3,1,3 / 2)$ & $(2 / 3,1,3 / 2)$ & $(1,1,1)$ & $(0.246,0.327,0.421)$ & 0,351 & 0,375 \\
\hline
\end{tabular}

\section{$(\mathrm{cc})$ EY}

This work is licensed under a Creative Commons Attribution 3.0 License. 